\title{
O ENADE COMO UM COMPONENTE CURRICULAR OBRIGATÓRIO: PERSPECTIVAS E DESAFIOS NO CONTEXTO DA GOVERNANÇA DE CURSOS ÁREA DA ENFERMAGEM
}

\author{
ENADE AS A MANDATORY CURRICULAR COMPONENT: PERSPECTIVES AND \\ CHALLENGES IN THE CONTEXT OF COURSE GOVERNANCE NURSING AREA
}

\author{
Thiago Henrique Almino Francisco \\ Pedro Antonio de Melo \\ Isadora Maria Back da Veiga
}

Resumo: Este artigo sistematiza um conjunto de atividades que foram apresentadas no Fórum das Escolas de Enfermagem que ocorreu na Universidade do Oeste de Santa Catarina (UNOESTE). A intenção das ações foi reunir um conjunto de elementos que permitissem o desenvolvimento de um diagnóstico, proporcionando a oportunidade de compreender o ENADE e o CPC como instrumentos de governança. Por meio de um estudo bibliográfico e documental, foi possível, por meio de um processo de triangulação, construir um conjunto sistemático que se consolidou em uma modelagem, que permite compreender o movimento de uma área ao longo dos ciclos trienais do ENADE. Os resultados permitem apresentar uma série de ações que contribuem com o movimento de acompanhando das ações, e que devem ser apropriados pelo NDE.

Palavras-Chave: ENADE. CPC. SINAES

\begin{abstract}
This article systematizes a set of activities that were presented at the Forum of Nursing Schools that took place at the University of Western Santa Catarina (UNOESTE). The intention of the actions was to gather a set of elements that allowed the development of a diagnosis, providing the opportunity to understand the ENADE and the CPC as instruments of governance. Through a bibliographic and documentary study, it was possible, through a process of triangulation, to construct a systematic set that was consolidated in a modeling, that allows to understand the movement of an area throughout the triennial cycles of the ENADE. The results allow us to present a series of actions that contribute to the accompanying movement of actions, which should be appropriated by the NDE.
\end{abstract}

Keywords: ENADE. CPC. SINAES 


\section{INTRODUÇÃO}

A partir de 2008, o Exame Nacional de Desempenho dos Estudantes (ENADE) torna-se o principal insumo para a composição do Conceito Preliminar de Curso (CPC), numa tentativa; que pode ser considerada bem-sucedida; de articular as ações de avaliação e de regulação no âmbito de cursos de graduação no ensino superior brasileiro. Contudo, este movimento ocorreu "à revelia" do aspecto sistêmico do SINAES, e após 10 anos se consolida como um indicador aplicado a governança dos cursos de graduação no Brasil.

Percebe-se ${ }^{1}$ que o CPC passa a compor um sistema robusto, composto por atividades e indicadores que ainda requerem uma compreensão organiza de seus desdobramentos, mas que de alguma forma tem proporcionado aspectos indutores da qualidade no sistema de ensino superior no Brasil. Para além de uma lógica financista ou "privatizante", o CPC tem percorrido um caminho distinto de sua concepção, especialmente pelo esforço de alguns pesquisadores que se ocupam de descortinar os desafios que estão relacionados a ele.

Baseado nestas reflexões, este trabalho se constitui na transcrição de uma atividade que foi desenvolvida no Fórum das Escolas de Enfermagem que ocorreu na Universidade do Oeste de Santa Catarina (UNOESTE), campus de Joaçaba, no dia 07 de junho de 2019. No evento, em conjunto com diversos coordenadores e professores que atuam na área da Enfermagem, algumas reflexões emergiram no sentido de compreender o ENADE e o CPC como instrumentos de governança.

Para tanto, o artigo se organiza em cinco seções. A primeira, com esta introdução, precede as contribuições teóricas que sustentam e os procedimentos metodológicos, que permitem a produção do diagnóstico da área de a apresentação de oportunidades que são proporcionadas pelos resultados do ENADE e do CPC na área da Enfermagem, que podem ser analisados na seção de número quatro. Por fim, as conclusões oferecem as contribuições da pesquisa e as sugestões para trabalhos futuros. 


\section{CONTRIBUIÇÕES TEÓRICAS: O SINAES E SEUS DESAFIOS}

O aspecto sistêmico do SINAES foi defendido pela primeira vez em $2006^{2}$, destacando o movimento que o sistema de avaliação poderia proporcionar, bem como a influência de seus resultados na gestão estratégica das instituições de ensino superior. Por meio dos diversos momentos do processo de avaliação institucional, haveria a possibilidade de analisar constantemente os "momentos" de uma determinada instituição e de um curso, sob a ótica de diversos instrumentos e de distintas metodologias. O resultado de tudo isso, destacam os autores, proporcionariam oportunidades de cumprir princípios estabelecidos pelo SINAES, especialmente naquilo que se referia a valorização da identidade de uma determinada instituição. A avaliação, portanto, deveria possuir uma visão equilibrada entre o percurso formativo e somativo, com predominante do primeiro e, neste aspecto, encontrava-se um dos primeiros desafios do sistema.

Ao longo da evolução do movimento da avaliação na perspectiva do SINAES, uma série de questionamentos emergiam em função do que vinha sendo percebido ao longo da implementação do sistema. Com o surgimento dos indicadores de qualidade, previstos inicialmente na Portaria Normativa No. 40, de 13 de dezembro de $2007^{3}$, o CPC e o Índice Geral de Cursos (IGC) foram considerados elementos que interferiram severamente no sistema, especialmente por restringir um dos processos considerados inovadores na perspectiva da avaliação. Emergem uma prática de "supervalorização" do ENADE, restringindo fortemente o potencial da autoavaliação já que os indicadores se alinhavam com a regulação e, em função da cultura já estabelecida desde a época do Provão, com os rankings.

Outra visão ${ }^{4}$ destaca que 0 movimento da avaliação é fundamental, especialmente da avaliação interna, para ampliar as oportunidades propostas pelo sistema e, principalmente, para confirmar os princípios que o SINAES trouxe para o campo do ensino superior no Brasil. A avaliação, em todos os seus momentos, deveria ser uma prática de acompanhamento sistemático das atividades político-pedagógicas das IES, fomentando análises críticas com a intenção de melhorar as atividades acadêmicas e administrativas de uma instituição de ensino superior, independentemente de sua categoria administrativa. 
Numa perspectiva mais crítica, há quem ${ }^{5}$ destaca o fato de que o SINAES, especialmente após o surgimento dos indicadores, se tornou um sistema altamente burocrático e ancorado em marcos legais complexos, as vezes difuso e bastante inconsistente. Em maio a portarias, decretos, instruções normativas e outros elementos jurídicos, o movimento do SINAES foi ganhando um corpo muito mais "legalista" do que "institucional", já que os esforços caminharam, em muitos espaços, apenas para o "cumprimento das regras" e não para um processo de reflexão-ação que era proposto desde a gênese do sistema. Dessa forma, a autora destaca a necessidade de revisitar os aspectos operacionais do sistema e torná-lo mais "orgânico" frente aos desafios que o campo do ensino superior vivência.

Nessa mesma linha, o trabalho a OCDE ${ }^{1}$ destaca que o SINAES é um sistema bastante importante para o ensino superior brasileiro, principalmente pela condição que possui de não permitir a entrada de instituições que não possuam as capacidades ideais para funcionar. Contudo, no mesmo relatório, destacam-se condições que podem ampliar a eficácia do sistema tais como a elaboração de fundamentos teóricos concretos, de melhoramentos em seus procedimentos estatísticos, da melhor organização dos indicadores e da compreensão do sistema.

Contudo, há também visões que defendem os indicadores. Uma delas ${ }^{6}$, destacada ainda que de forma preliminar no campo das produções sobre o tema demonstram ${ }^{7}$ que os indicadores começam a se tornar instrumentos de governança, permitindo que o SINAES se constitua como um movimento indutor da qualidade. Além disso, diversos instrumentos legais e normativos publicados a partir de 2017, entre eles os instrumentos de avaliação externa para os atos regulatórios de cursos e instituições, tem demonstrado uma tentativa de aproximar as avaliações "paralelas" existentes, compreendendo o SINAES como um movimento articulado, entre regulação e avaliação, e propondo, nos próprios instrumentos, movimentos articulados entre os momentos da avaliação institucional e os indicadores.

Nessa trilha, os principais desafios do SINAES, mesmo depois de 15 anos de funcionamento do sistema, residem na compreensão sistêmica de sua estrutura e na sensibilização, para que o sistema seja compreendido como um modelo de governança e não apenas como um rito burocrático ou cartorial. Em uma visão geral da contribuição dos autores escolhidos, percebe-se que, mesmo com diversas 
críticas, o SINAES ainda se apresenta como um elemento fundamental para a organização do sistema de ensino superior no Brasil e, como qualquer elemento inovador, deve continuar evoluindo para que se torne cada vez mais relevante no campo da gestão e da governança do ensino superior brasileiro.

\section{ORDENAMENTOS METODOLÓGICOS}

Este texto sistematiza uma contribuição que foi proporcionada ao Fórum das Escolas de Enfermagem que ocorreu na UNOESTE, ocasião na qual foi apresentado um conjunto de informações oriundas de uma investigação de cunho bibliográfico e documental com o objetivo de apresentar um exercício de diagnóstico de cursos de enfermagem, a partir dos resultados de desempenho da área do Conceito Preliminar de Cursos. Este conceito se origina, fundamentalmente, dos resultados da participação de um determinado curso no ENADE, que ocorre em um período de três anos para cada curso de graduação.

Do ponto de vista da classificação, esta pesquisa enquadra-se em uma perspectiva interpretativista, qualitativa, desenvolvida a partir de uma perspectiva bibliográfica e documental. Este estudo se pauta em uma condição específica ${ }^{8}$ de compreender um movimento particular ${ }^{9}$ a uma área, sem a pretensão de criar valorações quantitativas ou esquemas matemáticos para atender aos resultados. Busca-se, por meio de um aprofundamento documental e bibliográfico, reitera-se, a identificação de padrões ${ }^{10}$ de comportamento que possam ser considerados para minorar os desafios encontrados na percepção de desafios que ainda pairam sobre a avaliação institucional.

Em um movimento descritivo, as fontes de dados consultadas foram os Relatórios do INEP e as Sinopses que publicam os resultados do CPC, disponíveis no endereço eletrônico do Instituto Nacional de Estudos e Pesquisas Educacionais Anísio Teixeira (INEP). Foram consultados os Relatórios Sínteses de Área, mais especificamente o da área da "Enfermagem", o Relatório de Formação Geral, o Relatório de Língua Portuguesa e o Relatório de Curso. Para ilustrar os comparativos, foram escolhidos dois cursos que se encontram em extratos distintos de desempenho: um com CPC 5 e outro com CPC 3. 
Por meio de um exercício de triangulação dos dados, considerando a análise de conteúdo ${ }^{11}$ os resultados apresentam alguns padrões e desafios da área, materializados a partir do comparativo entre cursos com conceitos distintos, proporcionando uma oportunidade de reconhecer o movimento que ocorre na área e que pode ser utilizado como modelo para que se aplique em outras áreas de atuação.

\section{APRESENTAÇÃO DOS RESULTADOS}

Esta seção apresenta o exercício de diagnóstico proposto, considerando os desafios encontrados na área da Enfermagem, tendo como base os resultados do CPC 2016.

\section{UM EXERCICIO DE DIAGNÓSTICO}

A proposta de diagnóstico foi construída a partir da análise dos relatórios consultados, considerando o movimento da triangulação dos dados a partir destas fontes. O resultado disso, foi a possibilidade de mapear comportamentos comparativos que podem proporcionar alternativas que contribuam para o fomento de ações assertivas de gestão do ENADE e do CPC. A partir de tudo isso, também é possível oferecer um portfólio de sugestões que tenha a condição de "profissionalizar" a gestão destes elementos, contribuindo também para o movimento orgânico e organizado, em torno da avaliação, do PPC.

Nesse sentido, este trabalho está organizado em torno de um comparativo que parte de cursos com conceito 5 , permitindo que, a partir de um estudo comparado relacionado a um curso com conceito 3 , possa ser possível compreender padrões que possam tornar o CPC um movimento articulado com a governança de um curso de graduação na área da enfermagem.

O primeiro ponto a se destacar, está no quadro 3 , que demonstra o comportamento médio de cursos que possuem conceito 5 no CPC, com destaque para todos os insumos que compõem a estrutura do indicador. 


\begin{tabular}{|l|l|l|l|l|l|l|l|l|}
\hline \multicolumn{2}{|l|}{ Comportamento de cursos com CPC 5 } \\
\hline $\begin{array}{l}\text { Média } \\
\text { FG }\end{array}$ & $\begin{array}{l}\text { Média } \\
\text { CE }\end{array}$ & $\%$ Qs & $\begin{array}{l}\text { Média } \\
\text { IDD }\end{array}$ & \%QS & $\%$ MSc & $\%$ Dr & $\%$ RT & \\
\hline 60,93 & 57,90 & $71,2 \%$ & 4,87 & $97 \%$ & $\begin{array}{l}85 \\
100 \%\end{array}$ & $\begin{array}{l}79 \\
100 \%\end{array}$ & $\begin{array}{l}85 \\
100 \%\end{array}$ \\
\hline
\end{tabular}

Quadro 01: Comportamento médio de cursos de enfermagem com CPC 5 Fonte: INEP (2017)

A partir do tratamento dos dados das Sinopses Estatísticas do CPC e dos Microdados, com a colaboração dos relatórios sínteses de curso, disponibilizados pelo INEP, é possível conhecer o movimento que ocorre no âmbito de cursos com conceitos elevados, o que permite compreender padrões que são adotados por essas IES que atingem este patamar. Pontualmente, portanto, é possível destacar os seguintes elementos:

- Média FG: É a média obtida na prova de formação geral pelos concluintes, que é de, aproximadamente, 60,93;

- Média CE: É a média obtiva na prova de componente específico pelos concluintes, que é de, aproximadamente, 57,90;

- \%Qs: É o percentual de estudantes que consegue obter desempenhos nos quartis superiores da prova. Objetivamente, pode ser possível afirmar que há $71,2 \%$ de estudantes que conseguem desempenho superior a $75 \%$ na avaliação;

- Média IDD: É a média obtida no Indicador de Diferença de Desempenho, esperado e observado, que considera a nota do aluno concluinte na prova do ENADE e os resultados obtidos no ENEM;

- \%QSE: É o percentual de estudantes que preenchem o questionário do estudante com as métricas corretas, ou seja, escolhendo os valores " 5 " e "6" nas escalas que avaliam as condições de oferta do curso;

- \%MSC: é o percentual de docentes que possui o título de Mestre, informados no Censo da Educação Superior;

- \%DR: é o percentual de docentes que possui o título de Doutor, informados no Censo da Educação Superior; 
- \%RT: é o percentual de docentes que possui Regime de Trabalho integral ou parcial, tal como é informado no Censo da Educação Superior.

Com esse quadro exposto, torna-se possível promover comparativos entre cursos, de modo que seja possível compreender os movimentos que ocorrem no âmbito de cursos com conceitos distinto, ou então considerando um determinado posicionamento geográfico. A figura 02 , a seguir, apresenta um retrato que compara três cursos de Enfermagem, em um comparativo entre o Brasil, a região Sul e um curso do estado de Santa Catarina:

\begin{tabular}{|c|c|c|c|c|c|c|c|c|c|c|c|}
\hline & $\begin{array}{c}\text { Nota Bruta } \\
\text { (FG) }\end{array}$ & $\begin{array}{c}\text { Nota Bruta } \\
\text { (CE) }\end{array}$ & CONC. & ODP & INFRA & OAP & $\begin{array}{c}\text { Concluintes no } \\
\text { ENEM }\end{array}$ & IDD & N.MSC & N.DR & NRT \\
\hline BR & 62,93 & 58,95 & 4,81 & 4,97 & 4,69 & 5,00 & 5 & 5,00 & 3,82 & 1,73 & 2,13 \\
\hline SC & 47,54 & 44,94 & 2,79 & 4,44 & 4,24 & 3,85 & 6 & 3,49 & 5,00 & 4,25 & 5,00 \\
\hline Região & 44,90 & 43,46 & 2,54 & 4,41 & 4,74 & 4,36 & 31 & 2,77 & 4,13 & 1,92 & 3,98 \\
\hline
\end{tabular}

Figura 01: Um comparativo entre conceitos

Fonte: Elaborado pelo autor (2019)

A partir das notas em comparativo, é possível perceber os desafios que emergem em um determinado contexto, demonstrando desafios que podem ser explorados em um determinado plano de contingência. Entre o que se destaca, é possível apontar para elementos relativos ao desempenho do concluinte na prova do ENADE e elementos da composição do CPC. Considerando o CPC, a partir de um olhar que parte de cursos com conceito 5; que na figura é retratado como "BR"; os desafios que se apresentam estão relacionados as notas do questionário do estudante (ODP, INFRA e OAP) e em alguns pontos dos insumos do corpo docente, materializados nas notas de titulação e regime de trabalho. Uma das pistas que essa proposta proporciona, é um olhar mais profundo para o desempenho nas provas do ENADE.

Ao identificar as diferenças encontradas entre o curso de conceito 5 e os demais, buscou-se compreender a percepção dos estudantes na prova, por meio do estudo dos resultados do relatório sobre a percepção da prova, que está disponível no Relatório de Curso, resultante do preenchimento, por parte do estudante, do 
questionário de percepção sobre a prova. A Figura 03 apresenta o resultado deste exercício:

\begin{tabular}{|c|c|c|}
\hline \multicolumn{3}{|c|}{ Algumas variáveis sob a ótica do estudante } \\
\hline Percepção sobre a Prova & IES A & $B R$ \\
\hline $\begin{array}{l}\text { Você se deparou com alguma dificuldade ao } \\
\text { responder à prova. Qual? }\end{array}$ & $\begin{array}{l}57,5 \% \text { alegam abordagem diferente; } \\
10 \% \text { alegam desconhecimento de conteúdo }\end{array}$ & $\begin{array}{l}4 \% \text { alegam abordagem diferente; } \\
10 \% \text { alegam desconhecimento de conteúdo }\end{array}$ \\
\hline $\begin{array}{l}\text { Considerando apenas as questões objetivas da } \\
\text { prova, você percebeu que: }\end{array}$ & $\begin{array}{l}\text { 47,\% estudou e não aprendeu muitos dos } \\
\text { conteúdos }\end{array}$ & $80 \%$ estudou e aprendeu muitos dos conteúdos \\
\hline Tempo gasto & $\begin{array}{c}92,5 \% \text { - Entre } 2 \text { e } 4 \text { horas ( } 22,5 \% \text { permaneceu } \\
\text { apenas duas horas) }\end{array}$ & $100 \%$ - Entre 4 horas ou mais \\
\hline
\end{tabular}

Figura 02: Comparativo entre a percepção dos estudantes

Fonte: Elaborado pelo autor (2019)

Na figura 03, é possível identificar o comparativo das percepções sobre a prova manifestadas por estudantes de um curso com conceito 3 (IES A) e por um curso com conceito 5 (BR). Objetivamente, é possível destacar os seguintes aspectos:

- No curso com conceito 3,57,5\% dos estudantes alegam dificuldades relacionadas a "abordagem diferente de conteúdo", o que pode demonstrar diferenças entre a prova do ENADE e as avaliações que ocorrem no cotidiano do estudante. Indo um pouco mais além, este aspecto pode demonstrar que há desafios no percurso dos aspectos metodológicos preconizados pelo curso;

- No curso com conceito 5, percebe-se que $80 \%$ dos estudantes aprenderam todos os conteúdos. No curso com conceito 3 , os estudantes alegam que estudaram, mas não aprenderam;

- Outro ponto importante é o tempo de permanência na prova, que no curso com conceito 5 é acima de três horas.

A partir desse recorte, identificam-se outros elementos que podem complementar o exercício de diagnóstico, especialmente em se tratando do desempenho do ENADE. A Figura 04, a seguir, mostra o recorte do desempenho comparado do concluinte nas provas de formação geral, considerando um curso com conceito 3 (IES A) e um curso com conceito 5 (R). O que chama a atenção é o fato de que $100 \%$ dos estudantes do curso com conceito 5 possuem um desempenho acima de $50 \%$ da avaliação: 


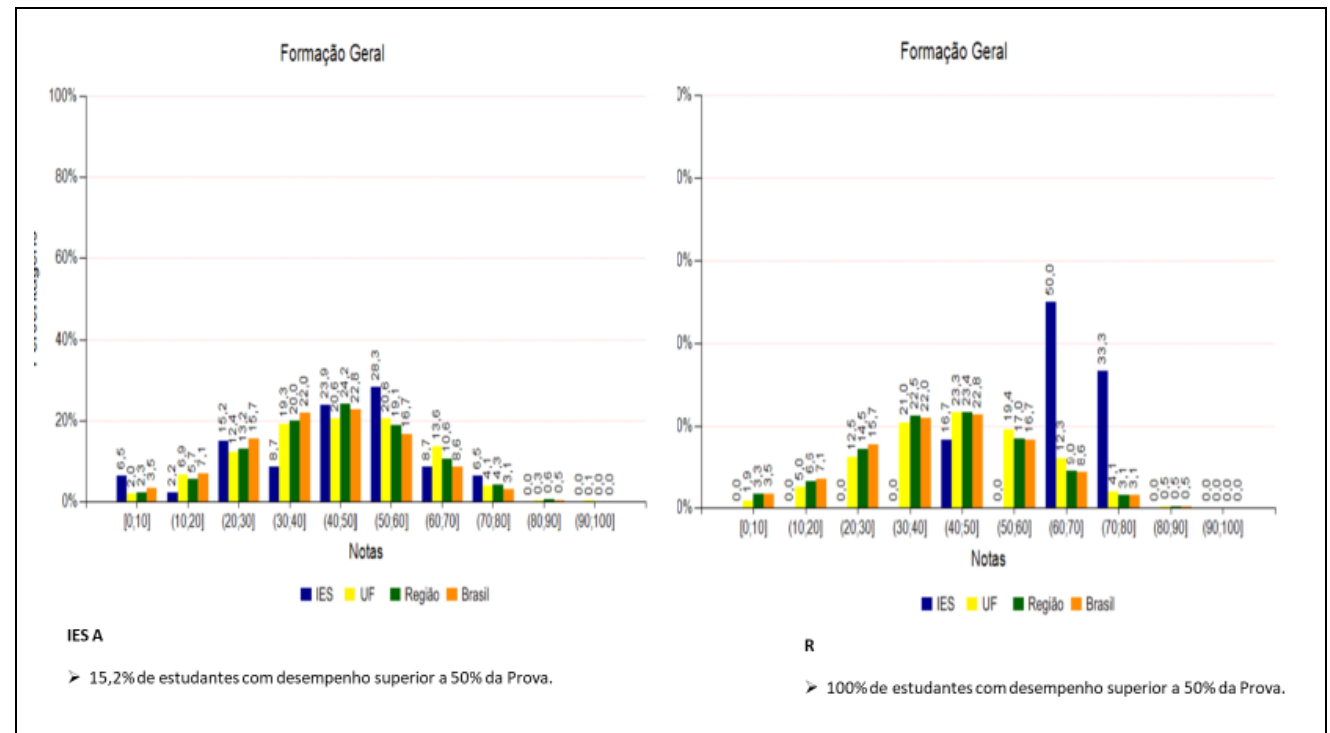

Figura 03: Comparativo entre a percepção dos estudantes Fonte: Elaborado pelo autor (2019)

A partir deste quadro, é possível ampliar a análise a partir da consulta ao Relatório Síntese de Formação Geral e ao Relatório Síntese de Língua Portuguesa. Do primeiro, é possível extrair os principais desafios encontrados pelos estudantes em função de seu desempenho nos referenciais do perfil do egresso, nas competências e nos objetos de conhecimento que compõem a matriz de prova do ENADE. Deste exercício, foi possível extrair os seguintes desafios que estão presentes no curso da "IES A", descritos na figura 05. Considera-se "desafio", o item que obteve desempenho abaixo da média nacional ou menor do que $50 \%$, tal como é exposto nos relatórios de curso: 


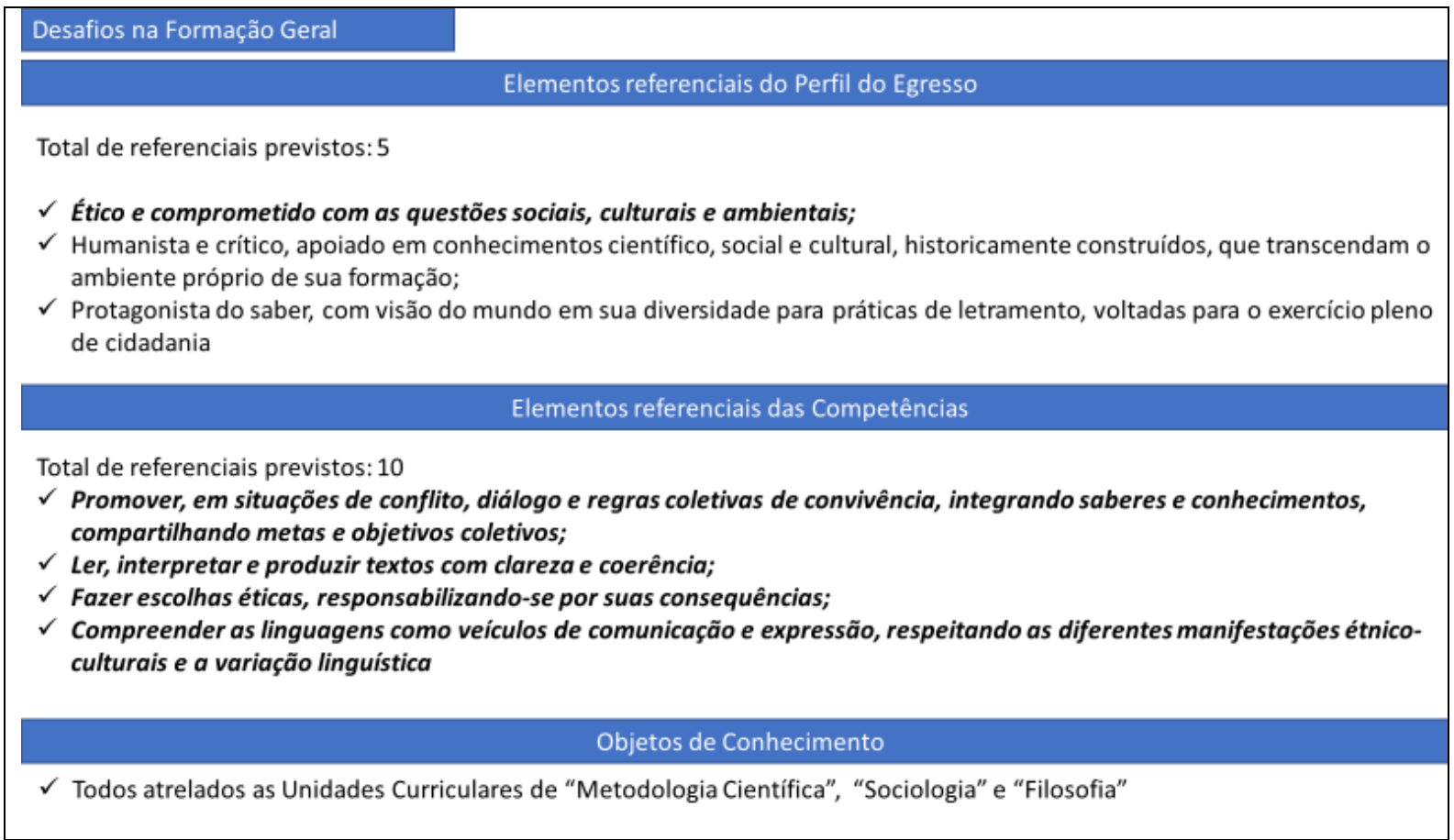

Figura 04: Desafios de formação geral do curso da "IES A"

Fonte: Elaborado pelo autor (2019)

O mesmo exercício foi feito com a parte de componente específico, cujo resultado é exposto na figura 06 . Nota-se que em um curso com conceito 5 há, pelo menos, $50 \%$ dos estudantes com desempenho superior a $50 \%$ da prova, enquanto no curso com conceito 3 este percentual é de pouco mais de 10\%. Isso permite inferir que cursos com conceitos elevados, costumam ter seus desempenhos ancorados nos quartis superiores da avaliação. 


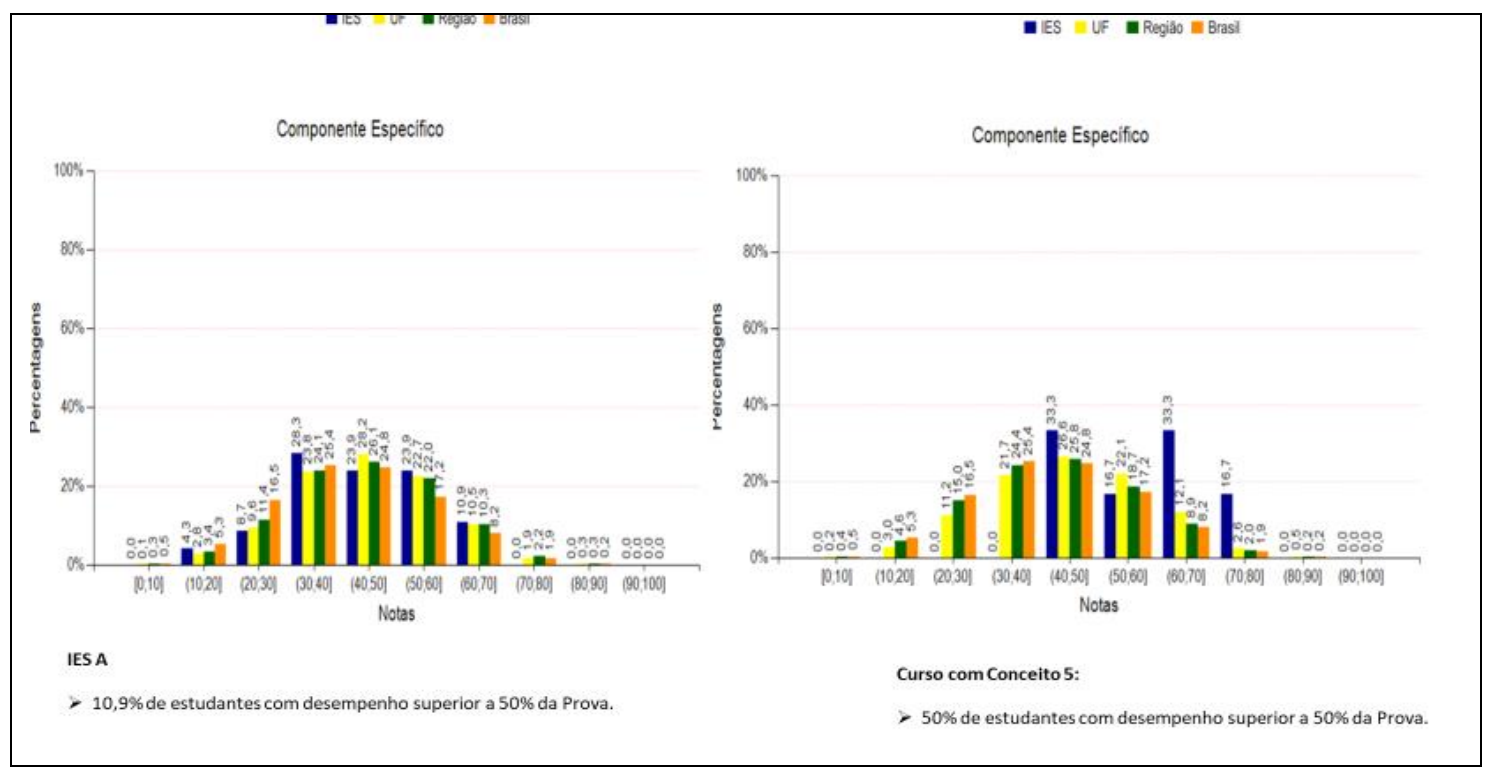

Figura 04: Comparativo de desempenho do componente específico do curso da "IES A"

Fonte: Elaborado pelo autor (2019)

A partir do que foi exposto na figura 06, o mesmo exercício pode ser realizado para identificar os desafios que são encontrados na perspectiva do componente específico. A figura 07 demonstra, de forma sistematizada, o que foi encontrado em um curso de Enfermagem com conceito 3 e que pode representar o mesmo desafio dos demais cursos com conceitos no mesmo patamar. A partir da sistematização dos dados, percebe-se que o curso de Enfermagem com conceito 3 apresenta desafios no que se refere aos referenciais do Perfil do Egresso, assim destacados:

$\checkmark$ responsável pela educação em saúde ao indivíduo, à família, ao grupo e à comunidade e pela educação permanente, capaz de promover sua própria educação e formação de futuros profissionais de enfermagem e saúde;

$\checkmark$ ético e humanista para o exercício profissional da enfermagem;

$\checkmark$ promotor do cuidado de enfermagem à saúde integral do ser humano em suas dimensões biopsicossociais, com responsabilidade social e compromisso com a cidadania;

$\checkmark$ crítico e reflexivo, com base científica e intelectual, para o cuidado de enfermagem ao indivíduo, à família, ao grupo e à comunidade; 
$\checkmark$ capaz de exercer a liderança para a tomada de decisões na administração e gerenciamento do cuidado de enfermagem, dos sistemas e organizações de saúde

Assim como na formação geral, esses elementos apareceram em itens que possuem desempenho abaixo da média nacional ou menor do que $50 \%$, considerando o que está exposto nos relatórios de curso, disponibilizados pelo INEP. Do ponto de vista das competências e dos objetivos de conhecimento, a figura 07 mostra um recorte deste resultado:

\begin{tabular}{|l}
\hline Desafios no Componente Específico \\
\hline Total de referenciais previstos: 12 \\
$\checkmark$ Todas foram desafios, pelo menos em uma questão \\
$\checkmark$ Competência VI se repete em três itens: integrar as ações de enfermagem às multiprofissionais de forma a diagnosticar $\epsilon$ \\
solucionar problemas de saúde, com base na comunicação interpessoal para a tomada de decisões e intervenções nc \\
processo de trabalho; \\
\\
Base de Consulta: DCNs \\
$\checkmark$ Educação e saúde; \\
$\checkmark$ Paciente crítico; \\
$\checkmark$ Gerencia de Enfermagem; \\
$\checkmark$ Humanização; \\
$\checkmark$ Estratégia de Saúde da Familia; \\
$\checkmark$ Metodologia Científica
\end{tabular}

Figura 06: Desafios de componente específico do curso da "IES A" Fonte: Elaborado pelo autor (2019)

Pelo exposto na Figura 07, percebe-se que, no caso do curso de conceito 3 , todas as competências previstas nas DCNs do curso foram consideradas desafios, já que há itens em que elas aparecem, por diversas vezes, avaliadas com scores abaixo do referencial utilizado para esse comparativo. Da mesma forma, diversos conhecimentos específicos da área são destacados, o que pode induzir um conjunto de práticas sugeridas como elementos indutores da qualidade no percurso do PPC, que serão, pontualmente, destacadas a seguir. 


\section{DESAFIOS E OPORTUNIDADES}

No campo da gestão da educação superior, mais especificamente no espaço ocupado pela avaliação institucional, o discurso do ENADE enquanto instrumento de governança parece ser recente. Mesmo após a promulgação do CPC, em 2008 e quando o ENADE se torna um instrumento relevante no percurso da regulação do ensino superior, o que se percebeu foram movimentos difusos e poucos avanços nos conceitos. Na área da Enfermagem, especialmente após os resultados de 2016, essa visão fica ainda mais explicita em função de uma queda sistemática no desempenho da área.

Em uma análise mais ampliada, percebe-se que poucos pesquisadores tem se debruçado com profundidade nos estudos que compreendem o ENADE como mecanismo de governança, sendo que a maioria dos estudos se preocupa em criticar o exame sob a ótica de uma perspectiva ideológica e outros estudos se apresentam bastante superficiais, sem referências da utilização de procedimentos metodológicos que preconizem os documentos produzidos pelo INEP.

Nesse sentido, considerando o exercício proposto neste artigo, e apresentado no Fórum das Escolas de Enfermagem, que ocorreu na Universidade do Oeste de Santa Catarina (UNOESTE), é possível consolidar um conjunto de atividades sistematizadas em um exercício de diagnóstico que permite a organização de uma modelagem, proposta na Figura 08 a seguir: 


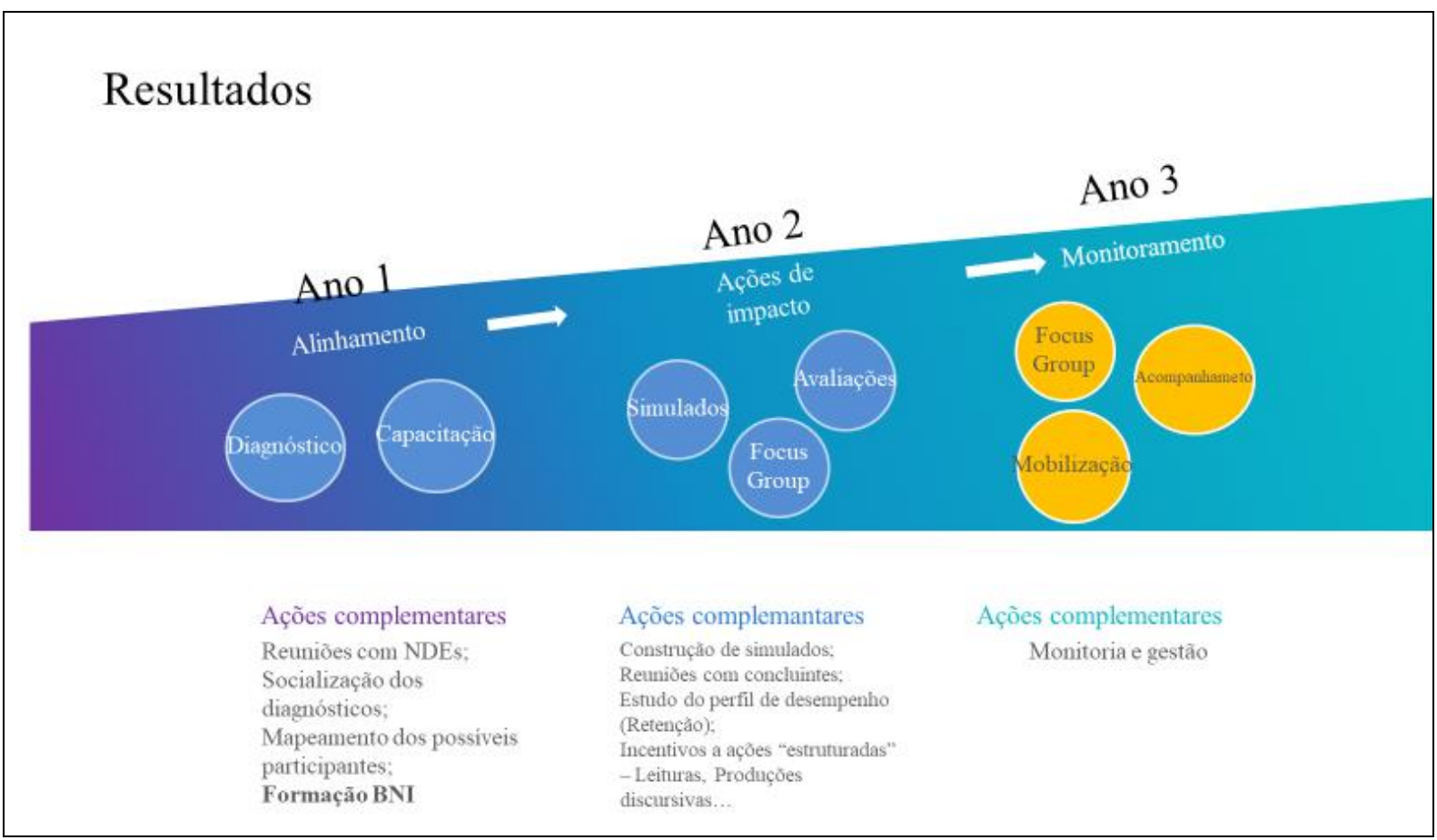

Figura 07: Modelagem proposta para o CPC como instrumento de governança Fonte: Elaborado pelo autor (2019)

Objetivamente, a intenção da proposta é tratar o CPC como um instrumento de governança, considerando todos os indicadores que compõem o conceito elementos estratégicos para a tomada de decisão. Exposto na Lei do SINAES, o ENADE deve ser compreendido como um "componente curricular obrigatório" e, por indução, inferese que os indicadores que compõem o CPC também devem possuir o mesmo cuidado. Dessa forma, descrita no modelo torna ambos os elementos estratégicos e parte do movimento pedagógico, proposto pelo PPC do Curso, proporcionando um trabalho trienal e sistemático:

- O "ano 1" é o ano de divulgação dos resultados do CPC que consideram a participação anterior de um determinado curso. Neste ano, após as divulgações, é onde ocorrem as atividades de "diagnóstico" e de "capacitações", permitindo que os NDEs tenham condições de se debruçarem nos dados disponíveis e nos resultados da área e dos cursos. Entre as ações, destacam-se a socialização dos diagnósticos e a formação docente, com evidência para o que se denominou de "Formação BNI" que tem a condição de abarcar uma das principais 
dificuldades dos estudantes na prova, que é a "Abordagem diferente de conteúdo";

- O "ano 2" é o ano das ações de impacto, em que os simulados, as atividades de conversa e sensibilização com os estudantes, e as avaliações (conduzidas pelo NDE e pela CPA) devem ocorrer com mais intensidade. A intenção aqui é descortinar desafios que ainda possam pairar no âmbito do grupo de estudantes, envolvê-los e conscientizá-los sobre a importância do exame. $O$ intuito deste processo é dialogar com - grupo de alunos, sobre os potenciais e limitações que serão encontradas no percurso até a realização da prova;

- O "ano 3" é o ano em que se desenvolvem ações de monitoria e gestão de tudo o que foi proposto, acompanhando a percepção do grupo de estudantes e implementando as mudanças estruturais necessárias para o CPC. Neste ano, o que se destacam são as mobilizações que devem ocorrer, mas sem prejuízo ao percurso do PPC.

Pela estrutura da proposta, há condições de desenvolver atividades que tenham, tanto no ENADE como no CPC, condições estratégicas e articuladas com o PPC, sem qualquer prejuízo a natureza do curso, ao percurso pedagógico do estudante ou aos componentes curriculares. Pelo teor da proposta, a intenção é proporcionar um ajuste cultural nos cursos de Enfermagem para que a avaliação se estabeleça como elemento norteador das ações estratégicas do curso.

\section{CONSIDERAÇÕES FINAIS}

Desde 2004, a avaliação institucional tem sido tema de pesquisa de um conjunto de pesquisadores, grupos de pesquisas e instituições, e na maioria das vezes a intenção dos estudos é compreender o movimento proporcionado por todos os momentos da avaliação institucional no Brasil. Contudo, a partir de 2008 , os estudos ganham uma conotação que busca compreender o fenômeno emergente da regulação no ensino superior brasileiro, com destaque para um movimento que tentou consolidar a compreensão do CPC enquanto instrumento norteador de ações estratégicas. 
Contudo, mesmo com a ênfase nesse viés, ainda é pequena a quantidade de estudos que buscam explorar o ENADE e o CPC como componentes curriculares de um PPC e como mecanismos de governança. Em uma breve busca sistemática, é possível encontrar poucos estudos que se ocupam dos materiais produzidos pelo INEP para o desenvolvimento de diagnósticos a respeito dos desempenhos e, menor ainda, o número de estudos que compartilham experiências sobre a utilidade destes indicadores.

Amparado neste pressuposto, este estudo ocupou este espaço e reuniu um conjunto de atividades que permitem explorar as contribuições do ENADE e do CPC como instrumentos de governança, considerando a área da Enfermagem como base para a aplicação do modelo. A proposta já foi desenvolvida em outras áreas, mais especificamente na Administração ${ }^{4}$, e vem sendo temas de trabalhos empíricos do autor ao longo de sua jornada profissional. Tal experiência tem encontrado "eco" nas mais diferentes áreas, proporcionando reflexões que tem aumentado o aprendizado sobre o tema.

Do ponto de vista das contribuições, espera-se que o estudo proporcione condições técnicas para que cursos da área da Enfermagem tenham condições de aumentar seus indicadores. Além disso, espera-se também que outras áreas possam se aproveitar o exercício de diagnóstico, proposto neste artigo, para atingirem patamares elevados em relação a compreensão do ENADE e do CPC como instrumentos de governança. Além disso, também há a intenção de fomentar a literatura sobre o tema, ocupando uma lacuna que há na literatura desde 2004. Ademais, aos trabalhos futuros, entre outros aspectos, sugere-se o relato de experiências de um curso que obteve êxito a partir do modelo proposto neste trabalho ou mesmo estudos de caso que procurem descortinar desafios expostos em cada uma das etapas propostas pelo modelo.

Por fim, é importante destacar que este estudo sistematizou uma atividade de diagnóstico discutida em um espaço de diálogo comum, de uma área específica. Há que se afirmar que é apenas uma contribuição, a partir de tantas outras possíveis, que não tem a intenção de esgotar a discussão sobre a temática. 


\section{REFERÊNCIAS}

1. OECD. Rethinking Quality Assurance for Higher Education in Brazil, Reviews of National Policies for Education, OECD Publishing, Paris. (2018)

2. RISTOFF, Dilvo; GIOLO, Jaime. O SINAES como sistema. Revista Brasileira de Pós-Graduação, v. 3, n. 6, 2006.

3. BRASIL. Portaria Normativa No 40, de 12 de dezembro de 2007. Institui o eMEC, sistema eletrônico de fluxo de trabalho e gerenciamento de informações relativas aos processos de regulação da educação superior no sistema federal de educação. Disponível em: http://download.inep.gov.br/download/condicoes_ensino/2007/Portaria_n40.pd f. Acesso em: 12/06/2019.

4. Francisco, T. H. A., de Melo, P. A., da Silva Nunes, R., Azevedo, M. I. N., \& Michels, E. A CONTRIBUIÇÃO DA AVALIAÇÃO IN LOCO COMO FATOR DE CONSOLIDAÇÃO DOS PRINCIPIOS ESTRUTURANTS DO SINAES. Avaliação: Revista da Avaliação da Educação Superior, 17(3). 2012.

5. GONÇALVES, Lukelly Fernanda Amaral. A autoavaliação na Universidade de Brasília: Entre a proposta do SINAES e os sinais da prática. Dissertação (2468 fls). Programa de Pós-Graduação em Educação da Universidade de Brasília. Brasília. 2016.

6. GRIBOSKI, Claudia Maffini; FUNGHETTO, Suzana Schwerz. O Sinaes e a qualidade da educação. Retratos da escola, v. 7, n. 12, p. 49-63, 2013.

7. FRANCISCO, Thiago Henrique Almino et al. Os indicadores de qualidade como instrumentos de governança: iniciando a experiência em um curso de Administração. ANAIS. Encontro Nacional dos Cursos de Graduação em Administração-Administração e Sustentabilidade. (ENANGRAD). Fóz do Iguaçu, 2015.

8. MORGAN, Gareth. Paradigms, metaphors, and puzzle solving in organization theory. Administrative science quarterly, p. 605-622, 1980.

9. FLICK, Uwe. Introdução à pesquisa qualitativa-3. Artmed editora, 2008.

10. STRAUSS, A.; CORBIN, J. Basics of qualitative research: grounded theory procedures and techniques. California: Sage Publication, 1991.

11. Bardin L. Análise de conteúdo. Lisboa: Edições 70; 1977.

12. BRASIL. Portaria Normativa No. $\mathbf{0 4}$, de 05 de agosto de 2008. Regulamenta a aplicação do conceito preliminar de cursos superiores, para fins dos 
processos de renovação de reconhecimento respectivos, no âmbito do ciclo avaliativo do SINAES instaurado pela Portaria Normativa no 1, de 2007. Ministério da Educação. Brasília. 2008.

13. BRASIL. Decreto No. 9.235, de 15 de dezembro de 2017. Dispõe sobre o exercício das funções de regulação, supervisão e avaliação das instituições de educação superior e dos cursos superiores de graduação e de pós-graduação no sistema federal de ensino. Presidência da República. Casa Civil. Subchefia para assuntos jurídicos. Brasília. 2017.

14. INEP. Instrumento de avaliação para $\mathbf{o}$ ato de reconhecimento e renovação de reconhecimento. Disponível em: http://download.inep.gov.br/educacao_superior/avaliacao_cursos_graduacao/i nstrumentos/2017/curso_reconhecimento.pdf. Acesso em: 12/06/2019.

15. BRASIL. Despacho No. 249, de 07 de dezembro de 2017. Secretaria de Regulação e Supervisão da Educação Superior. Ministério da Educação. Brasília. 2017. 